\title{
Lifecourse, immigrant status and acculturation in food purchasing and preparation among low-income mothers
}

\author{
Tamara Dubowitz ${ }^{1, *}$, Dolores Acevedo-Garcia ${ }^{2}$, Judy Salkeld ${ }^{2}$, Ana Cristina Lindsay ${ }^{3}$, \\ SV Subramanian ${ }^{2}$ and Karen E Peterson 2,3 \\ 'RAND Corporation, 4570 Fifth Avenue, Suite 600, Pittsburgh, PA 15213, USA: ${ }^{2}$ Department of Society, Human \\ Development and Health, Harvard School of Public Health, Boston, MA, USA: ${ }^{3}$ Department of Nutrition, Harvard \\ School of Public Health, Boston, MA, USA
}

Submitted 24 February 2006: Accepted 9 0ctober 2006

\begin{abstract}
Objectives: This study investigates how lifecourse, immigrant status and acculturation, and neighbourhood of residence influence food purchasing and preparation among low-income women with children, living in the USA. This research sought to understand physical and economic access to food, from both 'individual' and 'community' perspectives.

Design: This study used qualitative methodology (focus groups) to examine the mechanisms and pathways of food preparation and purchasing within the context of daily life activity for US- and foreign-born women, living in the USA. The study methodology analysed notes and verbatim transcripts, summarised recurring responses and identified new themes in the discussions.

Setting and subjects: A total of 44 women were purposively sampled from two metropolitan areas in Massachusetts, USA, based on (1) neighbourhood of residence and (2) primary language spoken. All focus groups were conducted in community health centres and community centres co-located with offices of the special supplemental nutritional programme for Women, Infants, and Children.

Results: Analysis of key response themes suggested that scarcity of food and physical access to food purchasing points did not influence food purchasing and preparation as much as (1) limited time for food shopping, cooking and family activities; and (2) challenges in transportation to stores and childcare. The study results demonstrated differing attitudes toward food acquisition and preparation between immigrant and US-born women and between women who lived in two metropolitan areas in the western and eastern regions of the state of Massachusetts, USA.

Conclusions: The findings illustrate 'hidden' constraints that need to be captured in measures of physical and economic access and availability of food. US policies and programmes that aim to improve access, availability and diet quality would benefit from considering the social context of food preparation and purchasing, and the residential environments of low-income women and families.
\end{abstract}

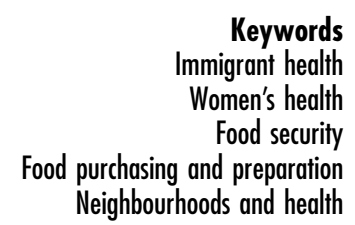

Women's health

Food security

Neighbourhoods and health
Residential neighbourhood characteristics, such as transportation, number of food stores present and measures of physical safety, are increasingly recognised to affect diet and diet-related disease among populations ${ }^{1-3}$. Research has suggested that limited transportation options, lack of shops and variety of foods available, and higher prices in low-income neighbourhoods are among the factors that have contributed toward suboptimal dietary intake among the poor ${ }^{4-6}$. Energy-dense diets high in added sugars and fats may be more affordable, and are consistent with lower food expenditures, low fruit and vegetable consumption and lower-quality diets in the poor and food-insecure ${ }^{7}$. Additionally, race-related disparity in healthy dietary intake has been hypothesised to be associated with differential neighbourhood effects by race on diet, demonstrated by varying reliance upon local food purchasing venues by race $^{6}$. In the case of immigrant populations, understanding the role of 'place' and health, or looking at food purchasing venues and use of local venues may allow us to better understand the pathway between local food environments and diet for different populations.

\section{Food security, immigrants, and maternal and child bealth}

In the USA, bousebold food security has been predominantly captured as the fiscal ability of a household to meet 'basic food needs' such that food insecurity causes 'the uneasy or painful sensation caused by a lack of food ${ }^{8}$. Food security as measured by the United States Department of Agriculture is defined as 'access by all people at all 
times to enough food for an active, healthy life', and is recognised as one of several conditions necessary for a population to be healthy and well nourished ${ }^{9}$. This conceptual perspective has not taken into account neighbourhood factors such as physical access to and geographic location of food purchasing venues. In other words, measuring only an individual's economic ability to buy food assumes that the physical and socio-cultural process of food acquisition is consistent from person to person and neighbourhood to neighbourhood. In contrast, the Food and Agriculture Organization of the United Nations (FAO) defines food security reflecting an understanding of the global distribution of food and resources. According to the FAO, food security exists when all people, at all times, have access to sufficient, safe and nutritious food to meet their dietary needs and food preferences for an active and healthy life ${ }^{10}$.

This study focused on a population of predominantly Latina and foreign-born (i.e. immigrant) women with young children living in the USA. Since 1990, the immigrant population in the USA has increased by $43 \%$ and accounts for the highest proportion of the total population since 1930. In 2002, 40\% of the Hispanic population was estimated to be foreign-born and $61 \%$ of Hispanic children have at least one foreign-born parent ${ }^{11}$. Moreover, the majority of Latina women in the USA between the ages of 25 and 39 years are mothers ${ }^{12}$.

Immigrants to the USA face cultural adaptations from language acquisition to basic changes in daily life and residence. While variation exists throughout the world as to 'the immigrant experience', many newcomers to the USA may experience changes in food variety, accessibility and availability. Limited research exists concerning changes in the way food is acquired, prepared and eaten by immigrants, and whether immigrant status has an impact on dietary intake, adequacy and quality.

Lifecourse experiences and family and social roles have been found to contribute differently toward dietary intake in low-to moderate-income adults ${ }^{13}$. The period following birth of a child is a time of exceptional transition in psychosocial and physical needs, time and role conflicts, and self-care and physical health for mother and child ${ }^{14}$. Changes in lifestyle and child-rearing responsibilities, alongside increased risk for social isolation and poor health status, can exacerbate already suboptimal dietary intake among low-income women ${ }^{14}$. Research has highlighted the obstacles many low-income mothers face, with limited social support such as childcare, access to transportation, time management skills and feelings of depression compared with that of middle-aged employed women $^{15}$.

This qualitative study examined whether and how structural constraints (e.g. availability of food purchasing places within the neighbourhood of residence; individual accessibility to public transportation facilities; and access to childcare) influenced food purchasing and preparation among low-income, predominantly Latina women residing in two urban areas in the northeastern USA.

\section{Methods}

Focus group discussions were used to elicit an understanding of the beliefs, preferences and behaviours of lowincome women, and to capture their perceptions of the economic and sociodemographic contexts in which they live ${ }^{16-18}$. All women recruited into the study had completed a 12-month period of participation in a randomised controlled intervention trial (RCT) of a nutrition and physical activity educational programme among multiethnic, postpartum women in two urban areas, Boston and Springfield/Holyoke, Massachusetts, USA ${ }^{14}$. Eligibility criteria for the RCT (and therefore all focus groups) were: (1) income eligibility to receive Women, Infants, and Children (WIC) programme benefits (i.e. household income $\leq 185 \%$ of the US federal poverty level based on family size (when the data were collected, in 2003, the US federal poverty level was US $\$ 18400$ for a family of four, so $185 \%$ of the US federal poverty level was US\$34040 per annum)); and (2) birth of an infant who was $<20$ weeks old to women at the time of enrolment. RCT participants in both the 'intervention' and 'control' treatment arms who had completed the follow-up survey were recruited for the qualitative study; at the time of the focus groups, women had children aged 13-18 months.

Focus group participants were purposively sampled geographically and by language spoken in order to build upon our main inquiries concerning immigrant status and neighbourhood of residence. Women were recruited based on (1) expressing an interest in participating in the focus groups at their RCT final survey interview; or (2) responding to letters of invitation sent to women whose RCT final interviews did not include the additional option of focus group participation. The study protocol of the RCT and the qualitative study reported here were reviewed and approved by the Institutional Review Board of participating institutions.

After women $(n=58)$ expressed interest in participating in the focus groups, all residential addresses were plotted, or geocoded, to a map of Massachusetts, and each point was labelled according to primary language spoken by the participant (English or Spanish). Appropriate locations to hold the discussion groups were chosen, based on the spatial distribution of potential participants, geographically and by language. All women were contacted by phone to invite them to participate in discussion groups. Women were also sent reminder flyers with directions. A standard US\$35 incentive as well as free childcare was offered for participation in the focus groups, reflecting local research practices in the study area.

Seven focus groups of 1.5-2 hours duration each were held over a 6-week period among immigrant Spanishspeaking women $(n=24)$ and US-born English-speaking 
$(n=20)$ women from the Boston and Springfield/Holyoke metropolitan areas. Groups were diverse in age, parity and educational level. All focus groups were conducted in community health centres co-located with WIC programme offices.

\section{Focus group guidelines and process}

The focus group protocol followed open-ended questions probing the location of neighbourhood food purchasing sites, food acquisition and food preparation. Additionally, questions were asked regarding whether and how access to transportation and childcare influenced food purchasing and preparation. Questions were developed with the assistance of Spanish- and English-speaking data collectors and staff of the RCT, capitalising on the knowledge and insights they had accumulated through administration of the surveys during the RCT. All seven focus groups were audio-taped and had a designated note-taker. All participants gave informed consent for tape recordings. Facilitators were trained in focus group moderation and facilitation to ensure implementation of a systematic protocol across focus groups. Training included review of the function and goals of the focus groups and guidance for the facilitator to maintain objectivity throughout the focus group. For Spanish-speaking groups, a native Spanish speaker moderated all groups; the lead author (T.D.) moderated all English-speaking groups. Spanishspeaking groups had a native Spanish-speaking note-taker, and one of the authors (J.S.) took notes for English-speaking groups. Following each focus group, notes were typed and audiotapes were fully transcribed. Transcripts from Spanish-speaking focus groups were translated into English by the bilingual group facilitator who led the group. Basic demographic characteristics of participants were obtained from linking to their RCT survey, used solely for purposes of obtaining these descriptive statistics of women who participated in the focus groups.

\section{Data analysis}

Transcriptions of focus group were summarised and then manually coded for emerging themes in a data index format. Notes were used to confirm the coded themes. Transcripts and notes were analysed by identifying recurring, emergent themes using the constant comparison method ${ }^{19,20}$. This qualitative method analyses data in stages, most notably (1) comparing incidents applicable to each category; and (2) integrating categories and their properties. This process undergoes continuous refinement throughout the data collection and analysis process, feeding back into the process of category coding. After noting patterns and cross-cutting themes throughout (time and childcare constraints, cultural role of food preparation and 'meals', social support) and clustering them by conceptual grouping (food preparation, acquisition and immigrant status), emergent relationships were identified across categories based upon the original research questions. Themes are presented textually, with quotes illustrative of emergent and cross-cutting themes.

\section{Results}

Demographic characteristics of focus group participants, shown in Table 1, were consistent with purposive sampling; half were from the Boston metropolitan area and half were from western Massachusetts (Springfield/

Table 1 Demographic characteristics of focus group participants

\begin{tabular}{lccc}
\hline & Boston & $\begin{array}{c}\text { Western } \\
\text { Massachusetts }\end{array}$ & Total \\
\hline First-generation immigrant to the USA (foreign-born) & 19 & 5 & 24 \\
Non-immigrant (US-born) & 3 & 17 & 20 \\
Race/ethnicity & & & \\
Latina & 20 & 7 & 27 \\
Black & 1 & 3 & 4 \\
White & 0 & 9 & 9 \\
Asian/Pacific Islander & 0 & 2 & 2 \\
American Indian & 1 & 0 & 1 \\
Other & 0 & 1 & 1 \\
Mean age (years) & & & 28.9 \\
Educational level & 0 & 1 & 1 \\
Elementary & 5 & 4 & 9 \\
Some high school & 8 & 7 & 25 \\
Completed high school & 3 & 9 & 12 \\
Some college & 1 & 0 & 1 \\
Associate degree & 2 & 2 & 4 \\
Bachelor's degree & 0 & 1 & 1 \\
Postgraduate degree & & & \\
Marital status & 13 & 15 & 28 \\
Married/living with partner & 9 & 7 & 16 \\
Separated/never married & & & \\
\hline
\end{tabular}


Holyoke). In Boston, 19 women were born outside the 50 United States (first-generation immigrant). Five women from western Massachusetts were first-generation immigrants and 11 had at least one of two parents born outside the USA (second-generation immigrant). All foreign-born women from Boston were Spanish-speaking and came from several locations in the Caribbean and Central America, including Puerto Rico, the Dominican Republic, El Salvador, Cuba and Mexico.

Figure 1 displays emergent themes and cross-cutting influences concerning 'time' and 'obstacles' from analysis of focus group data. There was also intersection between the social and geographical aspects to food purchasing and preparation and immigrant status: foreign-born women were less likely to perceive physical barriers to purchasing and preparation of food. For purposes of presentation, responses were grouped and compared within each topic area principally by women's immigrant status (foreign-versus US-born) and by geographic region of residence (western Massachusetts versus Boston metropolitan area).

\section{The social and geographical aspects of food purchasing}

Most women, regardless of neighbourhood or immigrant status, described food shopping practices as a combination of monthly or bi-monthly trips to 'no frills' stores that have advertised coupons or sales for large and/or staple foods. For small or necessary items such as milk or butter, women relied more upon convenience and proximity to a food store. Transportation to and location of grocery stores within neighbourhoods differed between western Massachusetts and Boston. Women in western Massachusetts relied much more on cars for transport and had a more limited choice of food stores. Women in Boston, on the other hand, spoke of many different food stores and various types of transportation in order to get there.

Among women from all groups, price was described as a key factor in choice of shopping locations.

'We are fans of watching the prices and of the savings. Since my busband is the only one working, when be gets back from work, we look at the specials and we compare the price... We use coupons. We look for specials and see if we can stretch the money'.

\section{Geographical access and food availability}

Some of the differences between foreign- and US-born women emerged through discussion of physical access to food purchasing places and its impact on food acquisition and preparation. US-born women were less inclined than immigrant women to travel great distances to grocery stores. Foreign-born women, however, spoke about their experience in the USA compared with that in their native country and many felt that food acquisition was easier for them in the USA.

I think that the transportation here is easier. It's different also in regards of food, here the poorest person it does not matter how educated they could be or not be it does no matter

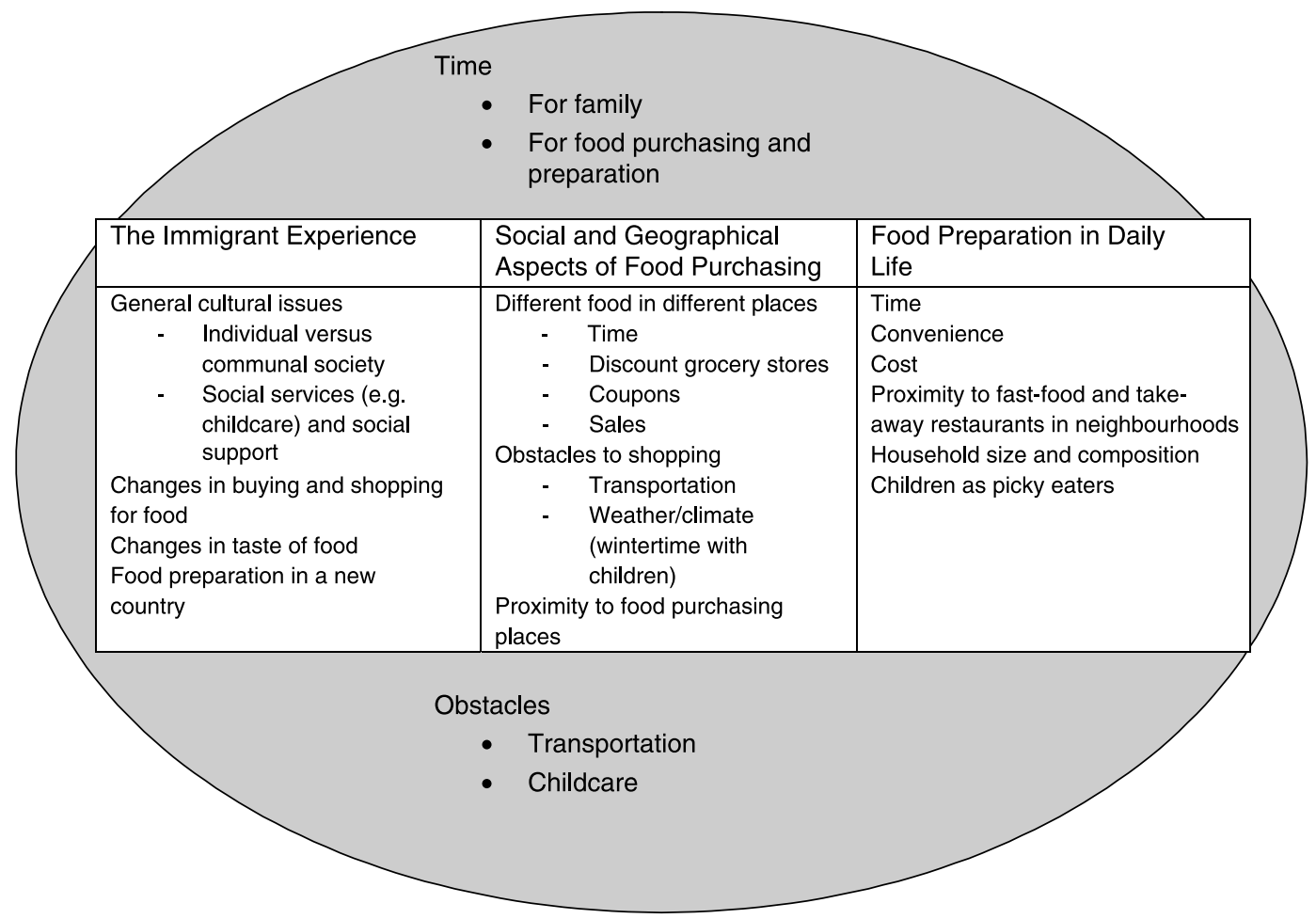

Fig. 1 Emergent and cross-cutting themes from focus group discussions 
what they do, there is always dollars to buy food. In our country it's not like that, people make \$100 a month and can't buy good food, here you can'.

Many of the immigrant women said that produce was better, cheaper and easier to find in the USA. However, many immigrant women also felt that although food was cheaper and more plentiful in the USA, it was of lower quality:

'The biggest difference is the meat and the chicken. Here, we need to put a lot of spice so it will have more flavor, instead the chicken in my country is exquisite'.

'It's the chemicals they use to conserve it, so it lasts longer. Over there they kill the cattle twice a week so you know it and you buy it fresh'.

Most women agreed that smaller stores in their neighbourhoods were very expensive and they frequented them only 'in emergencies' or for everyday items. Women spoke about the quality of products at these stores:

'Food is older there. I had the experience with the yuca and avocado that it was very expensive and rotten, and I said I won't buy there any more. I'm wasting my time, my money and getting bad things'.

In some focus groups, the difficulty of shopping with children was discussed:

I take the bus to Stop and Shop and to take the kids is a hassle. I'm by myself so I have to take the first one and make sure she gets on the bus and I'm like, "don't touch anyone, please". And then the second one, I have to bring him up. Then, to come back with the bags. It's hard'.

\section{Convenience and time}

Although many women reported buying ready-made food or meals once or twice per week, nearly all women were concerned with the cost of ready-prepared food. Many of the Spanish-speaking women questioned the taste and preparation of the foods. Foreign-born women, compared with US-born women, were more committed to purchasing appropriate and familiar ingredients as opposed to 'fast food.' By contrast, even within the Spanish-speaking cohort of women, those women who were born in the USA were more likely to buy already prepared food, either 'ready-to-serve' microwave meals or meals from fast-food restaurants or take-away establishments, than to travel to purchase different ingredients and goods from different stores. Yet many Spanish-speaking US-born women spoke about their preference for 'Spanish' restaurants over fastfood outlets.

Many of the English-speaking US-born women, on the other hand, were more willing to frequent fast-food outlets and purchase ready-prepared food, primarily because of convenience. The quality or nutritional value of the food was not as important to them. As explained by one USborn woman:

'... If we're somewhere and they're bungry ... how can I not? You know, we can stop off at McDonalds and get a cheeseburger and French fries. It's like a dollar'.

\section{Food preparation in daily life}

Food preparation practices ranged from a woman who reported that she does 'not think about' what she prepares, to a woman who made monthly calendars of different meals to prepare, to women who prepared very similar meals on a daily basis (rice, beans and either chicken or beef). Themes and factors that impinged on food preparation included time, convenience and children as 'picky' eaters.

Most women reported that they were the primary person responsible for food preparation and shopping. One woman said that she and her fiancé share all responsibility, and another woman, whose husband was a chef, explained that she did food purchasing and her husband did the preparation. Still, many women talked about difficulty cooking 'entire' meals. As a native-born woman from the Springfield area described:

I don't really have time to eat. I'll just make them [the children] something or I'll get take-out orders for them because I don't have time. I'll eat something like a granola bar'.

The influence of the length of the workday on food preparation emerged as a theme from respondents in all focus groups irrespective of language, nativity or immigrant status. As one woman said:

\section{'I work three days a week. I don't have time - for me. I} get bome late and I don't want to think about cooking'.

On the other hand, there were women who said they ate more nutritiously and were more conscious about eating fruit and vegetables and salads since having children.

Almost all women talked about time and convenience, especially those constrained by working or attending school. Women discussed the difficulty of cooking and caring for children at the same time. As one US-born woman from western Massachusetts described:

'My son ... sometimes it's just hard because be [my child] won't let me just cook... It's just that he feels like that is his time. I don't know'.

\section{Family and social aspects of food}

Both immigrant and US-born women consistently mentioned social ties around eating. Family structure and composition emerged as an important theme with respect to cooking. Many women discussed eating at extended 
family's homes. Single mothers in the groups, irrespective of immigrant status or neighbourhood of residence, explained that preparing full meals was not worth the time it took in households with fewer members.

'I go to my mom maybe twice a week. And then I go to my sister's once per week. It's just me and my daughter'.

Discussion around economic aspects of household food security was more difficult to elicit. Of the 44 women in the focus groups, just one woman, who was a single mother and native-born, grew up in one Boston neighbourhood and currently lives with her aunt in another neighbourhood, explained that even though geographic access to food was not a problem, household food distribution was challenging.

I live with my aunt now and she lives in Roxbury. I've been living there since August ... Everything is right there. The store, the hospital, bus stop... The McDonalds is right there. Save A Lot is right there. Church is right there. Laundromat is down the street'.

She goes on to explain that the reality of her situation at home, however, makes it difficult to think about having a healthy diet:

'It's hard to think about what's healthy. You just want to eat and do what you gotta do. If you're on the run, you can't stop and think about bealthy this or that. You think about some bread, meat, cheese, mayonnaise and then you're out'.

Themes defined by 'time' and 'family' in the USA were brought up repeatedly by women in the Spanish-speaking focus groups.

'Here, life is always running, especially for us. We have 3 children in different schools so life is complicated and if you do not try to distract your mind you'll end up stressed out or depressed'.

\section{Discussion}

Relationships between nativity, duration of US residence, acculturation and diet have been demonstrated in both national and community-based studies conducted in the USA. Despite lower socio-economic status than secondgeneration or White non-Hispanic women, first-generation Mexican-American women have demonstrated healthier dietary intakes ${ }^{21}$. Being born in the USA and reporting a preference for speaking English at home have been significantly associated with greater consumption of convenience foods and salty snacks, as well as greater frequency of eating higher-fat foods, overall ${ }^{22}$. While this research sought to examine the pathways through which access and availability influenced food purchasing and preparation among immigrant and US-born low-income mothers, many emergent themes were intertwined. For example, relationships between acculturation, lifecourse experiences, social contexts and physical context were demonstrated to be not only important in daily life activity, but especially central to the cultural phenomena of diet, food preparation and eating.

Other research has highlighted differences in how food security is conceptualised and experienced in different populations. Wolfe and colleagues demonstrated how the experience of acquisition, affordability and preparation of food influenced elders' experience of food security ${ }^{23}$. An augmented instrument of the food security survey module was developed for use among Spanish-speakers in the $\mathrm{USA}^{24}$. Still, this study demonstrated that 'food security', as measured in the USA primarily as economic access to food, may not capture some of the most important mechanisms associated with food acquisition, including lifecourse factors such as childcare and the need to work to make ends meet.

In focus groups with low-income Latina families in California, for example, it was found that women tend to reduce their food intakes during the winter in an attempt to spare other household members from experiencing hunger $^{25}$. Research in the UK has additionally shown how economic and physical access to food differs by variation in demographic groups (e.g. mothers of younger children versus the elderly $)^{26,27}$.

In the present study, women shared many of the same obstacles in finding time to shop and prepare food. Immigrant women, however, were more apt to view food preparation as an essential daily activity. US-born women, including second-generation immigrants, were more likely to consider at-home food preparation to be a choice and spoke more about buying 'take-away' foods and fast food, and eating at relatives' houses. In this way, one could expect that the context of the neighbourhood, specifically the quality and quantity of prepared food purchasing venues (such as take-away restaurants and fast-food establishments), would have more influence among USborn women and second-generation immigrants (and less effect on immigrant women). Likewise, US-born women were less likely to speak about going to different food stores and generally did their shopping at one or two places. Again, this would imply that US-born women are more vulnerable to neighbourhood constraints such as limited variety or quality of food choice in the neighbourhood.

Many immigrant women explained that weekends were a time for family and friends in their country of origin, but in the USA this time was used for necessary household activity, such as food preparation and purchasing. In this way, food preparation and meals might be a central family function in their country of origin but a secondary activity in the USA - which could translate into lower-quality meals. For example, prepared and processed foods are nutritionally less optimal, but faster and more convenient 
to prepare. In an unpublished study with Hispanic women in Durham, North Carolina, fast food accessibility was one of the reasons cited regarding their families' diets deteriorating in quality ${ }^{28}$. Among other findings, this study confirmed that time constraints had a strong influence on the decision to purchase ready-made 'fast food'.

In this study, there were varying degrees to which women relied upon their 'neighbourhood' of residence. For example, immigrant women living in the Boston metropolitan area described travelling from one end of the city to the other in order to acquire different ingredients. Similarly, women in western Massachusetts, who by and large had access to personal cars, reported travelling to the 'better of the two' grocery stores. Yet USborn women were less likely to spend time travelling long distances to acquire ingredients. Varying factors that might come into play include household size and access to transportation.

\section{Limitations}

One of the limitations in this research was the geographic division of women - between immigrant status and between metropolitan areas. Many of the immigrant women lived in the Boston metropolitan area. Thus, the research was unable to disentangle fully whether, for example, food shopping practices were linked with immigrant status or with neighbourhood of residence. This division of women into neighbourhoods and immigrant status is partly the result of the complex nature of neighbourhood segregation, immigrant enclaves and urban history, and was largely unavoidable with this methodology. The research was designed so that women who lived in the same neighbourhood and spoke the same language participated in focus groups together.

The incentive of US\$35 given to all women who participated may have been appealing to women who were more 'in need' of money, making them more eager to attend, or to those who who were resourceful. Because participants in the parent RCT were all lowincome women with infants, it is more likely that women's capacity to participate in focus groups was limited by social responsibilities and roles, and those who attended had more social support, had fewer children and/or did not work at a part-time or full-time job outside the home.

A further limitation of this work concerns the cultural and linguistic challenges English-speaking researchers face in conducting research with Latina women, many of whom speak Spanish. Information derived in Spanish may have a different cultural connotation and meaning from information derived in English. Yet because the focus groups were semi-structured (meaning discussion and conversation helped lead the order and types of questions that were asked), women were encouraged to express themselves in their native language and words. Verbatim transcripts were translated prior to analysis.

\section{Conclusion}

This research contributes to the development of a more complete definition of 'food security'. The research questions sought to understand food security in a broader context, in order to draw attention to immigrant health and the effect of neighbourhoods on health. In this way, food programmes, research and policy can start to take both neighbourhoods and specific populations into account when designing and implementing their efforts. Additionally, evaluation of such programmes should capture their operation in the varying contexts and levels within which they work.

If food security is defined as physical and economic access to an adequate and healthy supply of food, these notions - of space and/or time - must be conceptualised as part of the way food security is evaluated and improved. Still, it is important to recognise that differences in place (i.e. neighbourhood) characteristics matter. In this light, policymakers must consider the social context of individuals, within places, when initiating health promotion efforts.

This research demonstrated that in order effectively to measure and influence household food security, neighbourhood factors must be considered. With this, food policy and programmes can more productively act on the very purpose they serve. Efforts can be made on a local level - such as promoting the use of establishments that are geographically accessible and supply a variety of foods. On a state level, officials can devote more attention to the importance of neighbourhoods in health and nutrition outcome.

These findings have potential implications for the design and implementation of multilevel environmental intervention studies. Social context, as described through this research, may provide an additional way of examining the connection of neighbourhood residents to the food environment. Further, this work highlights the need for more qualitative research in this area, which has the ability to highlight the mechanism and pathways by which 'place' and 'health' are connected. For example, this research was able to uncover how food purchasing points or other services used by certain groups, general willingness and ability to travel for groceries, and specific priorities might influence the decisions and behaviours of different population groups.

Immigrants comprise one in nine US residents and one in four low-wage workers ${ }^{29}$. The immigrant population is central to the economy of the USA and their health and well-being is of fundamental importance. This study and others have established that the physical and social characteristics of neighbourhoods influence nutritional behaviour. Thus, food policy and 
programmes that seek to address food security and improve diet would become more effective with consideration of people and of their residential environments. After all, improving food security is not limited to improving fiscal access on an individual level, but should include minimising the social, cultural and environmental barriers to a healthy diet.

\section{Acknowledgements}

Sources of funding: This work was supported generously by the Department of Maternal and Child Health at the Harvard School of Public Health (Maternal and Child Health Bureau training grant MCHB 5T76 MC 00001); the Vitamin Settlement Grant, State of Massachusetts; the intervention trial, Reducing Disease Risk in Low-income, Postpartum Women 1 R01 HD37368-01 (NICHD) (Peterson, PI); the Ruth L Kirschstein National Research Service Award (NRSA) F31-NS046161-02 Pre-doctoral Fellowship; and the Center for Minority Health, University of Pittsburgh Graduate School of Public Health export grant 5P60MD-000207-04.

Conflict of interest declaration: The authors declare no conflicts of interests with respect to this research.

Authorship responsibilities: T.D. conceptualised and designed the study, attended all focus groups, performed the analyses, and wrote the manuscript. J.S. helped organise focus groups and participated in conceptualisation of the research. A.C.L. helped with conceptualisation of the research. D.A.G., S.V.S. and K.E.P. helped with conceptualisation of the study, guidance of the analysis and interpretation of the results.

Acknowledgements: The authors wish to thank each of the women who took the time and effort to share their stories in the focus groups. We also wish to thank Carrie Hardwick and Aidana Baldassarre for their painstaking and generous effort with organisation, implementation and facilitation of focus groups. In addition, Aidana Baldassarre was responsible for all translation of groups and of notes from Spanish to English.

\section{References}

1 Morland K, Wing S, Diez-Roux A. The contextual effect of the local food environment on residents' diets: the Atherosclerosis Risk in Communities Study. American Journal of Public Health 2002; 92: 1761-7.

2 Van Lenthe FJ, Mackenbach JP. Neighborhood deprivation and overweight: the GLOBE study. International Journal of Obesity 2002; 26: 234-40.

3 Robert SA, Reither EN. A multilevel analysis of race, community disadvantage, and body mass index among adults in the US. Social Science \& Medicine 2004; 59: 2421-34.

4 Curtis KA, McClellan S. Falling through the safety net: poverty, food assistance and shopping constraints in an American city. Urban Anthropology 1995; 24: 93-135.
5 Turrell G. Structural, material and economic influences of the food purchasing choices of socioeconomic groups. Australian and New Zealand Journal of Public Health 1996; 20: $11-7$.

6 Morland K, Wing S, Diez Roux A, Poole C. Neighborhood characteristics associated with the location of food stores and food service places. American Journal of Preventive Medicine 1996; 22: 23-9.

7 Drewnowski A, Specter SE. Poverty and obesity: the role of energy density and energy costs. American Journal of Clinical Nutrition 2004; 79: 6-16.

8 Bickel G, Nord M, Price C, Hamilton W, Cook J. Guide to Measuring Housebold Food Security. Number 6 in the Series Measuring Food Security in the United States: Reports of the Federal Interagency Food Security Measurement Project. Alexandria, VA: US Department of Agriculture, Food and Nutrition Service, Office of Analysis, Nutrition, and Evaluation, 2000.

9 Bickel G, Nord M, Price C, Hamilton W, Cook J. Guide to Measuring Household Food Security, Revised 2000. Alexandria, VA: US Department of Agriculture, Food and Nutrition Service, 2000.

10 Food and Agriculture Organization. Rome Declaration on World Food Security and World Food Summit Plan of Action [online], 1998. Available at http://www.fao.org/docrep/003/ w3613e/w3613e00.HTM

11 Lollock L, ed. Profile of the Foreign-born Population in the United States 2000. Current Population Reports. Washington, DC: US Census Bureau, US Department of Commerce, Economics and Statistics Administration, 2001.

12 Bachu A, O'Connell, M. Fertility of American Women: Population Characteristics. Current Population Reports [online], 2000. Available at http://www.census.gov/prod/ 2000pubs/p20-526.pdf

13 Devine CM, Wolfe WS, Frongillo EAJ, Bisogni C. Life course events and experiences: association with fruit and vegetable consumption in three ethnic groups. Journal of the American Dietetic Association 1999; 99: 309-14.

14 Peterson KE, Sorensen G, Peason M, Hebert JR, Gottlieb BR, McCormick MC. Design of an intervention to improve dietary and activity patterns among low-income, postpartum women. Health Education Research 2002; 5: 531-40.

15 French SA, Neumark-Sztainer D, Story M, Jeffery RW. Reducing barriers to participation in weight-loss programs in low-income women. Journal of the American Dietetic Association 1998; 98: 198-200.

16 Patton MQ. Utilization-focused Evaluation: The New Century Text. Thousand Oaks, CA: Sage, 1996.

17 Yin RK. Case Study Research, Design and Methods. Thousand Oaks, CA: Sage, 1994.

18 Lindsay AC. Integrating quantitative and qualitative methods to assess the impact of child survival programs in developing countries: the case of a program evaluation in Ceara, Northeast Brazil. Health Education Behavior 2002; 29: 570-84.

19 Glaser B, Strauss AL. The Discovery of Grounded Theory. New York: Aldine de Gruyer, 1967.

20 Strauss A, Corbin J. Basics of Qualitative Research (Grounded Theory Procedures and Techniques). Thousand Oaks, CA: Sage, 1990.

21 Guendelman S, Abrams B. Dietary intake among MexicanAmerican women: generational differences and a comparison with white non-Hispanic women. American Journal of Public Health 1995; 85: 20-5.

22 Norman S, Castro C, Albright C, King A. Comparing acculturation models in evaluating dietary habits among low-income Hispanic women. Ethnicity \& Disease 2004; 14: 399-404.

23 Wolfe WS, Frongillo EA, Valios P. Understanding the experience of food insecurity by elders suggests ways to 
improve its measurement. Journal of Nutrition 2003; 133 2762-9.

24 Harrison GG, Stormer A, Herman DR, Winham DM. Development of a Spanish-language version of the U.S Household Food Security Survey Module. Journal of Nutrition 2003; 133: 1192-7.

25 Melgar-Quinonez HR, Kaiser LL. Relationship of childfeeding practices to overweight in low-income MexicanAmerican preschool-aged children. Journal of the American Dietetic Association 2004; 104: 1110-9.
26 Whelan A, Wrigley N, Warm D, Cannings E. Life in a 'food desert'. Urban Studies 2002; 39: 2083-100.

27 Wrigley N. Food deserts in British cities: policy context and research priorities. Urban Studies 2002; 39: 2029-40.

28 Jones S, Bentley M. Telling food stories: understanding the community context of household food security. Presented at Experimental Biology 2002: Understanding the Human Genome, New Orleans, LA, USA, 20-24 April 2002.

29 The Urban Institute [online]. Available at http://www. urbaninstitute.org. Accessed July 2004 